\title{
Transmembrane domain-mediated Lck association underlies bystander and costimulatory ICOS signaling
}

\author{
Zurong Wan ${ }^{1,2,3,4,5}$, Xingxing Shao ${ }^{1,2,3,4,5}$, Xingyu $\mathrm{Ji}^{4,5,6}$, Lihui Dong ${ }^{1,4}$, Jiacheng Wei $\mathrm{i}^{1,2,3,4,5}$, Zhuqing Xiong ${ }^{1,4}$, Wanli Liu ${ }^{4,5,6}$ and \\ Hai Qi (iD) $1,2,3,4,5$
}

The B7-family inducible costimulator (ICOS) activates phosphoinositide-3 kinase (PI3K) and augments calcium mobilization triggered by the T-cell receptor (TCR). We surprisingly found that the entire cytoplasmic domain of ICOS is dispensable for its costimulation of calcium mobilization. This costimulatory function relies on the unique transmembrane domain (TMD) of ICOS, which promotes association with the tyrosine kinase Lck. TMD-enabled Lck association is also required for p85 recruitment to ICOS and subsequent PI3K activation, and Lck underlies both the bystander and costimulatory signaling activity of ICOS. TMD-replaced ICOS, even with an intact cytoplasmic domain, fails to support $\mathrm{T}_{\mathrm{FH}}$ development or GC formation in vivo. When transplanted onto a chimeric antigen receptor (CAR), the ICOS TMD enhances interactions between T cells and antigen-presenting target cells. Therefore, by revealing an unexpected function of the ICOS TMD, our study offers a new perspective for the understanding and potential application of costimulation biology.

Cellular \& Molecular Immunology (2020) 17:143-152; https://doi.org/10.1038/s41423-018-0183-z

\section{INTRODUCTION}

The inducible costimulator (ICOS) molecule is a CD28-family costimulatory receptor that is upregulated by $\mathrm{T}$ cells following antigen stimulation. ${ }^{1,2}$ While ICOS is expressed by all recently activated T cells in vivo, its expression level is particularly high on follicular T-helper $\left(\mathrm{T}_{\mathrm{FH}}\right)$ cells, the $\mathrm{CD}^{+}{ }^{+}$-cell subset that specializes in promoting the germinal center response and humoral immunity. ${ }^{3}$ It is well established that ICOS is crucial for the development and function of $\mathrm{T}_{\mathrm{FH}}$ cells and is thus required for the germinal center reaction and affinity-matured antibody responses. $^{4-10}$ At the cellular level, ICOS functions in two context-dependent modes in vivo. ${ }^{11}$ In the bystander mode, ICOS on activated $T$ cells is engaged by follicular B cells that do not present antigen but constitutively express ICOS ligand (ICOSL). This bystander engagement of ICOS does not involve concomitant TCR triggering but enhances PI3K activation in the T cells, which promotes T-cell motility and follicular recruitment. ${ }^{12}$ In the costimulatory mode, on the other hand, ICOS promotes TCRdependent CXCR5 upregulation during priming interactions with antigen-presenting dendritic cells. ${ }^{9,13,14}$ During antigen-specific interactions between $T_{F H}$ cells and cognate $B$ cells in the follicle and the germinal center, ICOS enhances TCR-dependent calcium mobilization, which drives efficient CD40L externalization from vesicular stores in T cells and subsequent delivery to interacting $B$ cells. ${ }^{15}$

At the molecular level, however, it is not yet clear how ICOS signals to accomplish these cellular functions. Previous reports have established that when tyrosine-phosphorylated, the conserved YMFM motif in the ICOS cytoplasmic domain recruits the regulatory subunit $\mathrm{p} 85$ of phosphoinositide- 3 kinase $(\mathrm{PI} 3 \mathrm{~K})$ and activates the PI3K pathway. ${ }^{4,16,17}$ Importantly, constitutive p85 binding to ICOS can be detected in recently activated T cells without overt TCR stimulation or ICOS ligation, and ICOS ligation further enhances p85 binding and PI3K activation. ${ }^{12,16,18}$ Given that no kinase is known to associate with ICOS, it is not clear how ICOS can be constitutively phosphorylated and bound with p85 and how this recruitment is enhanced after its own crosslinking.

In contrast to PI3K activation, ICOS ligation alone does not trigger calcium flux, and ICOS-enhanced calcium mobilization strictly depends on concomitant TCR stimulation. ${ }^{15}$ ICOS costimulation of TCR-triggered calcium flux was originally thought to be a secondary effect of ICOS-driven PI3K activation. ${ }^{17,19}$ However, upon analyzing a knockin mouse strain carrying the ICOS ${ }^{\mathrm{Y} 181 \mathrm{~F}}$ allele, which renders the ICOS YMFM motif phosphorylationincompetent, Gigoux and colleagues demonstrated that the ability to activate PI3K is not required for ICOS to costimulate calcium mobilization. ${ }^{18}$ What actually underlies ICOS-mediated calcium costimulation therefore remains unclear.

In the current study, we surprisingly found that the entire cytoplasmic domain of ICOS is not necessary for its costimulation of TCR-triggered calcium mobilization. Instead, the unique transmembrane domain (TMD) of ICOS promotes its weak but constitutive association with the tyrosine kinase Lck and thereby augments proximal TCR signaling to enhance calcium mobilization. Furthermore, the unique ICOS TMD is also required for $\mathrm{p} 85$ recruitment and normal PI3K activation following ICOS ligation, a process that also depends on Lck. Therefore, by associating with Lck in a TMD-dependent manner, ICOS can constitutively signal through PI3K-dependent pathways without ligand interactions, enhance its Lck association and consequent PI3K activation upon

\footnotetext{
${ }^{1}$ Tsinghua-Peking Center for Life Sciences, Tsinghua University, 100084 Beijing, China; ${ }^{2}$ Laboratory of Dynamic Immunobiology, Institute for Immunology, 100084 Beijing, China; ${ }^{3}$ Department of Basic Medical Sciences, School of Medicine, 100084 Beijing, China; ${ }^{4}$ School of Life Sciences, 100084 Beijing, China; ${ }^{5}$ Beijing Key Lab for Immunological Research on Chronic Diseases, 100084 Beijing, China and ${ }^{6}$ MOE Key Laboratory of Protein Sciences, Tsinghua University, 100084 Beijing, China Correspondence: Hai Qi (qihai@tsinghua.edu.cn)
}

Received: 17 September 2018 Accepted: 30 October 2018

Published online: 6 December 2018 
144

receptor ligation and, when coligated together with the antigen receptor complex, augment the proximal signaling output by providing an extra pool of Lck.

\section{MATERIALS AND METHODS}

Mice

B6 (Jax 664), $\operatorname{lcos}^{-1-}$ (Jax 4859), OVA $323-339$-specific TCR transgenic OT-II (Jax 4194), and HEL-specific Ig-transgenic MD4 (Jax 2595) mice were originally from the Jackson Laboratory. All mice were maintained under specific pathogen-free conditions and used in accordance with governmental and institutional guidelines for animal welfare.

\section{ICOS-expressing Jurkat cells}

The parental Jurkat cell line was a kind gift from Dr. Chenqi Xu. Lentivirus was produced in 293T cells cotransfected with the psPAX2 and pMD2.G packaging plasmids together with a pHAGE vector that expresses wild-type ICOS or various mutant ICOS molecules and GFP. For lentiviral transduction, $5 \times 10^{5}$ Jurkat cells in the logarithmic growth phase were spin-infected at $1500 \times g$ with appropriate viral supernatants in the presence of $4 \mu \mathrm{g} / \mathrm{ml}$ polybrene (Sigma-Aldrich) for $2 \mathrm{~h}$ at $32^{\circ} \mathrm{C}$. Transduced Jurkat cells were subsequently propagated and used either as bulk culture or after further sorting of $\mathrm{GFP}^{+}$Jurkat cells by flow cytometry to $>99 \%$ purity.

Lck-deficient Jurkat cells

A subline of Jurkat cells that performs well in electroporation, a kind gift from Dr. Yun-Cai Liu, was used to create Lck-deficient Jurkat cells. The cells were electroporated with MSCV-based GFPtagged vectors that express Cas9 and Lck-targeting guide RNAs. Single $\mathrm{GFP}^{+}$Jurkat cells were cloned by sorting and were genotyped by PCR. Two Jurkat clones (clone 1 and clone 16) that lacked the guide RNA-targeted fragment from exon 2 to exon 9 were selected for subsequent experiments after validation by Western blotting (see Figure S5 for details). For experiments involving ICOS stimulation or immunoprecipitation in the absence of Lck, these Lck-deficient Jurkat cells and corresponding wildtype control cells were further transduced with ICOS-expressing constructs as described above.

\section{Calcium mobilization assay}

Pilot experiments were conducted to determine the anti-CD3 antibody concentration optimal for observation of the ICOSmediated costimulation of calcium mobilization in primary mouse $T$ cells and in the Jurkat $T$ cell line.

Regarding the primary mouse $\mathrm{T}$ cells, $\mathrm{CD} 4^{+} \mathrm{T}$ lymphocytes were isolated by CD4 Microbeads (Miltenyi Biotec) from $\mathrm{ICOs}^{-/-}$mice and activated with plate-bound anti-CD3 and anti-CD28 antibodies (Bio X Cell) in complete RPMI 1640 media. Retroviral transduction of these T cells with desired ICOS-expressing constructs or an empty vector was performed as previously described. ${ }^{12}$ Transduced $T$ cells were typically cultured for 4 days before use. To assay calcium flux, cells $\left(10^{7}\right.$ per $\left.\mathrm{ml}\right)$ were stained with $2 \mathrm{mM}$ Indo1 (Invitrogen) in RPMI medium without serum at $37^{\circ} \mathrm{C}$ for $30 \mathrm{~min}$, washed twice with ice-cold RPMI containing $1 \%$ serum, and then incubated in ice-cold RPMI containing $1 \%$ serum with biotinylated anti-CD3 (145-2C11, eBioscience, $2.5 \mu \mathrm{g} / \mathrm{ml})$ and/or biotinylated anti-ICOS antibodies (C398.4A, BioLegend, $5 \mu \mathrm{g} / \mathrm{ml}$ ) at a final cell density of $4 \times 10^{6}$ per $\mathrm{ml}$ for $1 \mathrm{~h}$. The cells were washed twice with RPMl containing $1 \%$ serum and brought to $37^{\circ} \mathrm{C}$ to read baseline Indo-1 fluorescence signals by flow cytometry for $1 \mathrm{~min}$, followed by an additional 4-min recording after streptavidin was added to the cell suspension at a final concentration of $50 \mu \mathrm{g} / \mathrm{ml}$. To minimize the effects of tube-to-tube variation, $\mathrm{GFP}^{+}$and GFP cells in the same tube were compared to determine ICOSmediated costimulation.
Jurkat cells $\left(5 \times 10^{6}\right.$ per $\left.\mathrm{ml}\right)$ were stained with $2 \mathrm{mM}$ Indo-1 (Invitrogen) in $\mathrm{HBSS}$ at $37^{\circ} \mathrm{C}$ for $30 \mathrm{~min}$, washed once, and then suspended in Ringer's solution containing $2 \mathrm{mM} \mathrm{Ca}^{2+}$. Cells $(2 \times$ $10^{6}$ per $\mathrm{ml}$ ) were then incubated with biotinylated anti-CD3 (OKT3, BioLegend, $0.2 \mu \mathrm{g} / \mathrm{ml}$ ) and biotinylated anti-ICOS antibodies (C398.4A, BioLegend, $2 \mu \mathrm{g} / \mathrm{ml}$ ) at room temperature for $1 \mathrm{~min}$. Indo-1 fluorescence was then measured for $1 \mathrm{~min}$, followed by an additional 4-min recording after streptavidin was added to the cell suspension at a final concentration of $50 \mu \mathrm{g} / \mathrm{ml}$. For certain experiments, Indo-1-loaded Jurkat cells were suspended in calcium-free Ringer's solution to incubate with biotinylated antiCD3 and biotinylated anti-ICOS antibodies, baseline Indo-1 fluorescence was read for $1 \mathrm{~min}$, streptavidin was added to a final concentration of $50 \mu \mathrm{g} / \mathrm{ml}$ to monitor Indo-1 fluorescence for another $2 \mathrm{~min}$, and $\mathrm{Ca}^{2+}$ was added to a final concentration of 2 $\mathrm{mM}$ for an additional 3-min recording. Where applicable, GFP Jurkat cells were spiked into individual tubes containing different $\mathrm{GFP}^{+}$transduced Jurkat cells to minimize the potential impacts of tube-to-tube variation on data interpretation, and each experiment was always conducted with its own GFP' control for batch variations of the stimulating reagents.

Immunoprecipitation and Western blotting

To probe p85 in ICOS immunoprecipitates after ICOS stimulation, $2 \times 10^{7}$ Jurkat cells were suspended in $100 \mu \mathrm{l}$ of serum-free RPMI, mixed with $100 \mu \mathrm{l}$ of prewarmed serum-free RPMI containing the anti-ICOS antibody (C398.4A, $10 \mu \mathrm{g} / \mathrm{ml}$, BioLegend) and a goat anti-hamster secondary antibody $(20 \mu \mathrm{g} / \mathrm{ml}$, Invitrogen), and then incubated at $37^{\circ} \mathrm{C}$ for $1 \mathrm{~min}$. The cells were then washed with 10 $\mathrm{ml}$ of precooled PBS and lysed on ice for $10 \mathrm{~min}$ with $500 \mu \mathrm{l}$ of RIPA buffer that contained $50 \mathrm{mM}$ Tris- $\mathrm{Cl} \mathrm{pH}=7.4,0.25 \%$ sodium deoxycholate, $150 \mathrm{mM} \mathrm{NaCl}, 10 \mathrm{mM}$ EDTA, $1 \%$ protease inhibitor cocktail (Bimake), and 2\% phosphatase inhibitor (Bimake). After centrifugation at $21,000 \times g$ for $10 \mathrm{~min}$ to remove debris, $3 \%$ of the lysate was taken as input, and the remaining lysate was incubated with $20 \mu \mathrm{l}$ of Protein A/G PLUS agarose beads (Santa Cruz) overnight at $4{ }^{\circ} \mathrm{C}$. The beads were then washed five times with icecold RIPA buffer, and the immunoprecipitates were eluted by adding $40 \mu \mathrm{l}$ of SDS-containing sample buffer and boiling at $100^{\circ}$ $\mathrm{C}$ for $10 \mathrm{~min}$. To prepare immunoprecipitates from unstimulated control cells, Jurkat cells were kept on ice for $10 \mathrm{~min}$ before the addition of $100 \mu \mathrm{l}$ of precooled serum-free RPMl containing the anti-ICOS antibody (C398.4A, BioLegend, $10 \mu \mathrm{g} / \mathrm{ml}$ ) and a secondary antibody (goat anti-hamster, $20 \mu \mathrm{g} / \mathrm{ml}$, Invitrogen) and further incubation on ice for $5 \mathrm{~min}$. These cells were then washed, lysed, and subjected to immunoprecipitation in parallel with the stimulated cells.

To probe mCherry-tagged Lck in ICOS immunoprecipitates, $3 \times$ $10^{7}$ Jurkat cells were suspended in $700 \mu$ l of precooled serum-free RPMI containing the anti-ICOS antibody (C398.4A, $10 \mu \mathrm{g} / \mathrm{ml}$, BioLegend) and then incubated on ice for $30 \mathrm{~min}$. The cells were then washed with $10 \mathrm{ml}$ of precooled PBS and lysed on ice for 10 min with $700 \mu \mathrm{l}$ of Brij97 buffer containing $20 \mathrm{mM}$ HEPES $(\mathrm{pH}=$ 7.4), $150 \mathrm{mM} \mathrm{NaCl}, 1 \%$ Brij97, 1\% protease inhibitor cocktail (Bimake), and $2 \%$ phosphatase inhibitor (Bimake). After centrifugation at $21,000 \times g$ for 10 min to remove debris, $3 \%$ of the lysate was taken as input, and the remaining lysate was incubated with $30 \mu$ of Protein A/G PLUS agarose beads (Santa Cruz) overnight at $4{ }^{\circ} \mathrm{C}$. The beads were then washed three times with ice-cold Brij97 buffer and once with detergent-free buffer containing $20 \mathrm{mM}$ HEPES ( $\mathrm{pH}=7.4)$ and $150 \mathrm{mM} \mathrm{NaCl}$, and the immunoprecipitates were eluted by adding $40 \mu \mathrm{l}$ of SDS-containing sample buffer and boiling at $100^{\circ} \mathrm{C}$ for $10 \mathrm{~min}$.

To probe phospho-Akt, $3 \times 10^{5}$ Jurkat cells were washed twice with PBS, suspended in $50 \mu \mathrm{l}$ of serum-free RPMI, and further mixed with $50 \mu \mathrm{l}$ of prewarmed antibody mixture containing the anti-ICOS antibody (C398.4A, $10 \mu \mathrm{g} / \mathrm{ml}$, BioLegend) and a goat anti-hamster secondary antibody $(20 \mu \mathrm{g} / \mathrm{ml}$, Invitrogen). The cells 
were incubated at $37^{\circ} \mathrm{C}$ for the indicated periods. The reactions were terminated by adding $100 \mu$ of $2 \times$ TNE containing $0.1 \mathrm{M}$ Tris$\mathrm{Cl}(\mathrm{pH}=8.0), 4 \mathrm{mM}$ EDTA, $2 \%$ Triton $\mathrm{X}-100,2 \%$ protease inhibitor cocktail (Bimake), and $4 \%$ phosphatase inhibitor (Bimake) and incubating on ice for $10 \mathrm{~min}$. The lysates were cleared by centrifugation at $21,000 \times g$ for $10 \mathrm{~min}$ at $4{ }^{\circ} \mathrm{C}$.

To probe phospho-ZAP70 and phospho-PLCY, $10^{6}$ Jurkat cells were washed twice with PBS and suspended in $25 \mu \mathrm{l}$ of serum-free RPMI. The cell suspension was mixed with $25 \mu$ l of prewarmed antibody cocktail containing biotinylated anti-CD3 (OKT3, $0.4 \mu \mathrm{g} /$ $\mathrm{ml}$, BioLegend) and/or biotinylated anti-ICOS (C398.4A, $4 \mu \mathrm{g} / \mathrm{ml}$, BioLegend) and incubated at $37^{\circ} \mathrm{C}$ for $1 \mathrm{~min}$. The cell suspension was then further mixed with $50 \mu \mathrm{l}$ of prewarmed streptavidin solution $(100 \mu \mathrm{g} / \mathrm{ml})$ and incubated for $30 \mathrm{~s}$. The reaction was terminated by adding $100 \mu \mathrm{l}$ of $2 \times$ TNE containing $0.1 \mathrm{M}$ Tris-Cl $(\mathrm{pH}=8.0), 4 \mathrm{mM}$ EDTA, $2 \%$ Triton-100, $2 \%$ protease inhibitor cocktail (Bimake), and 4\% phosphatase inhibitor (Bimake) and incubating on ice for $10 \mathrm{~min}$. The lysates were cleared by centrifugation at $21,000 \times g$ for $10 \mathrm{~min}$ at $4{ }^{\circ} \mathrm{C}$.

The antibodies used for Western blotting included anti-p85 (Cell Signaling Technology), goat anti-ICOS (R\&D), anti-Akt (Cell Signaling Technology), anti-phospho-Akt (Ser473) (D9E, Cell Signaling Technology), anti-phospho-Akt (Thr308) (Cell Signaling Technology), anti- $\beta$-actin (EASYBIO), anti-phospho-ZAP-70 (Tyr309)/Syk (Tyr352) (Cell Signaling Technology), anti-ZAP-70 (99F2) rabbit mAb (Cell Signaling Technology), anti-phospho-PLC $\gamma$ (Tyr783) (Cell Signaling Technology), anti-PLCY1 (DH910) XP rabbit mAb (Cell Signaling Technology), anti-Lck (3A5, Santa Cruz), antiFyn (FYN-59, Santa Cruz), goat anti-rabbit IgG-HRP (Easybio), goat anti-mouse IgG-HRP (Easybio), and donkey anti-goat IgG-HRP (Santa Cruz). The anti-mouse ICOS antibody used for Western blotting was a polyclonal antibody raised against the mouse ICOS extracellular domain from R\&D (Cat\# AF168). Due to glycosylation, ICOS is detected by this reagent as a smeared band between 34 and $43 \mathrm{kD}$ and an additional band of approximately $26 \mathrm{kD}$ when cells are lysed with NP-40 or as two to three bands of approximately 34 kD when lysed with Brij97.

\section{BiolD}

The basic method was previously developed, ${ }^{20}$ and the Bir $A^{*}-$ coding vector was a kind gift of Dr. R. J. O'Sullivan. Jurkat cells transduced with BirA*-fused ICOS or ICOS-CD44TM were cultured in complete RPMI media supplemented with $50 \mu \mathrm{M}$ biotin for $24 \mathrm{~h}$. Cells $\left(5 \times 10^{7}\right.$ per group) were washed with ice-cold PBS three times to remove free biotin before being lysed with $2 \mathrm{ml}$ of RIPA buffer. The samples were kept on ice for $10 \mathrm{~min}$ prior to centrifugation at $21,000 \times g$ for $10 \mathrm{~min}$ to remove debris, and $3 \%$ of the lysate was taken from each sample as input prior to streptavidin pull-down. The remaining lysate of each sample was mixed with $50 \mu$ l of Dynabeads M-280 Streptavidin (Invitrogen) and incubated on a rotator at room temperature for $1 \mathrm{~h}$. The beads were then washed with PBS containing 0.1\% BSA 5 times, and the precipitates were eluted by adding $40 \mu \mathrm{l}$ of SDScontaining sample buffer and boiling at $100^{\circ} \mathrm{C}$ for $10 \mathrm{~min}$.

Assay of ICOS-Lck colocalization by TIRF microscopy

Jurkat $T$ cells were placed on planar lipid bilayers (PLBs) that presented anti-ICOS antibodies. The PLBs were prepared as previously described. ${ }^{21}$ Briefly, biotin liposomes were prepared by sonication of 1,2-dioleoyl-sn-glycero-3-phosphocholine and 1,2-dioleoyl-sn-glycero-3-phosphoethanolamine-cap-biotin (Avanti Polar Lipids, Inc.) in a 25:1 molar ratio in PBS at a lipid concentration of $5 \mathrm{mM}$. Lab-Tek chambers (Thermo Fisher Scientific) were prepared with nanostrip-washed coverslips. The coverslips were incubated with $0.1 \mathrm{mM}$ biotin liposomes in PBS for $30 \mathrm{~min}$ at $37^{\circ} \mathrm{C}$. After washing, the PLBs were incubated with 50 $\mathrm{nM}$ streptavidin for $30 \mathrm{~min}$ and then washed to remove excess streptavidin. The streptavidin-containing PLBs were further incubated for $30 \mathrm{~min}$ with $2 \mu \mathrm{g} / \mathrm{ml}$ biotinylated anti-ICOS antibody (C398.4A), blocked with $1 \%$ casein in PBS at $37^{\circ} \mathrm{C}$ for $30 \mathrm{~min}$ and washed extensively with PBS before use. To evaluate ICOS-Lck colocalization, Jurkat T cells that expressed EGFP-tagged ICOS or ICOS-CD44TM and mCherry-tagged Lck were placed and incubated at $37^{\circ} \mathrm{C}$ on the anti-ICOS antibody-incorporated PLBs for 10 min. The cells were then fixed with $1 \%$ paraformaldehyde for 30 $\min$ at $37^{\circ} \mathrm{C}$. The TIRF plane of individual cells was imaged using an Olympus IX-81 microscope equipped with a TIRF port, ANDOR iXon + DU-897D EMCCD camera, and Olympus 100x TIRF lens (1.49 NA oil). EGFP and mCherry were illuminated with 488-nm and 561-nm lasers, respectively (Coherent). Each imaged cell was analyzed using the colocalization function of Imaris (Bitplane), which took into account the point spread function of the imaging system, automatically calculated the colocalization, and yielded the Pearson's correlation coefficient between the EGFP-ICOS and mCherry-Lck fluorescence for each cell.

Functional rescue of $I \cos ^{-1-} \mathrm{T}$ cells with ICOS variants in vivo Retrovirus was produced as previously described ${ }^{12}$ by transfecting Plat-E cells with an MSCV-based vector that expresses wild-type ICOS or mutant ICOS molecules together with IRES-GFP. I $\cos ^{-1-}$ OTII CD4 T lymphocytes were isolated from spleens with CD4 Microbeads (Miltenyi Biotec) and activated with plate-bound antiCD3 and anti-CD28 antibodies (Bio X Cell). Retroviral transduction of $\mathrm{T}$ lymphocytes was performed as previously described. ${ }^{12}$ The transduced cells were sorted based on GFP expression levels. Equivalent surface ICOS levels among different groups were confirmed by surface staining of ICOS. To test the ICOS variants for CXCR5 upregulation, $2 \times 10^{7}$ sorted T cells were adoptively transferred into $\mathrm{B} 6$ recipients and parked for 3 days before the recipients were immunized with $50 \mu \mathrm{g}$ of OVA protein in alum together with $5 \mu \mathrm{g}$ of LPS. CXCR5 expression on these T cells was assayed by flow cytometry 1 day after immunization. To test the ICOS variants for GC formation, $5 \times 10^{5}$ sorted $T$ cells were cotransferred together with $5 \times 10^{5} \mathrm{MD} 4 \mathrm{~B}$ cells into $\mathrm{B} 6$ recipients, which were immunized subcutaneously with $130 \mu \mathrm{g}$ of HEL-OVA conjugate antigen $^{22}$ in alum supplemented with $1 \mu \mathrm{g}$ of LPS 2 days later. The frequencies of MD4 GC B cells and OT-II $T_{F H}$ cells were measured by flow cytometry 5 days after immunization.

\section{T-B conjugation assay for ICOS TM-modified CAR}

Jurkat cells $\left(10^{4}\right.$ per reaction) expressing standard CD19-reactive $\mathrm{BBz}$ CAR that contained CD8TM as the transmembrane domain (a kind gift from Dr. Chenqi $\mathrm{Xu}$ ) or the ICOSTM-swapped version (ICOSTM-BBz CAR) were mixed with $10^{5}$ TAMARA-labeled Farage B cells, centrifuged in a U-bottomed 96 -well plate at $500 \times \mathrm{g}$ for 3 $\mathrm{min}$, and then incubated at $37^{\circ} \mathrm{C}$ for $0.5 \mathrm{~h}$. After vortexing for $40 \mathrm{~s}$, the frequencies of conjugates were enumerated by flow cytometry as previously described. ${ }^{23}$ The Jurkat $T$ cells were identified by GFP fluorescence provided by the CAR-expressing construct. Three technical replicates were assayed for each condition in every independent experiment.

\section{RESULTS}

The cytoplasmic domain of ICOS is not required for its costimulatory function

To understand how ICOS may costimulate TCR-triggered calcium mobilization, we constructed a series of ICOS mutants, including a cytoplasmic domain-truncated version called ICOS-NT (Figure S1), and tested whether these mutant molecules could enhance TCRtriggered calcium mobilization when retrovirally transduced into primary $\mathrm{ICOS}^{-1-}$ mouse T cells. As expected from previous findings by Gigoux and colleagues, ${ }^{18}$ the Y181F mutation did not affect surface ICOS expression (Figure S2A) and did not reduce calcium mobilization (Figure S2B). Unexpectedly, however, ICOS-NT was also able to costimulate calcium mobilization (Figure S2B). 
A

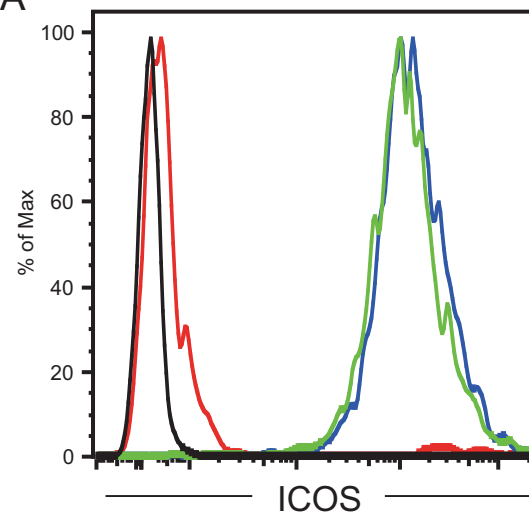

C
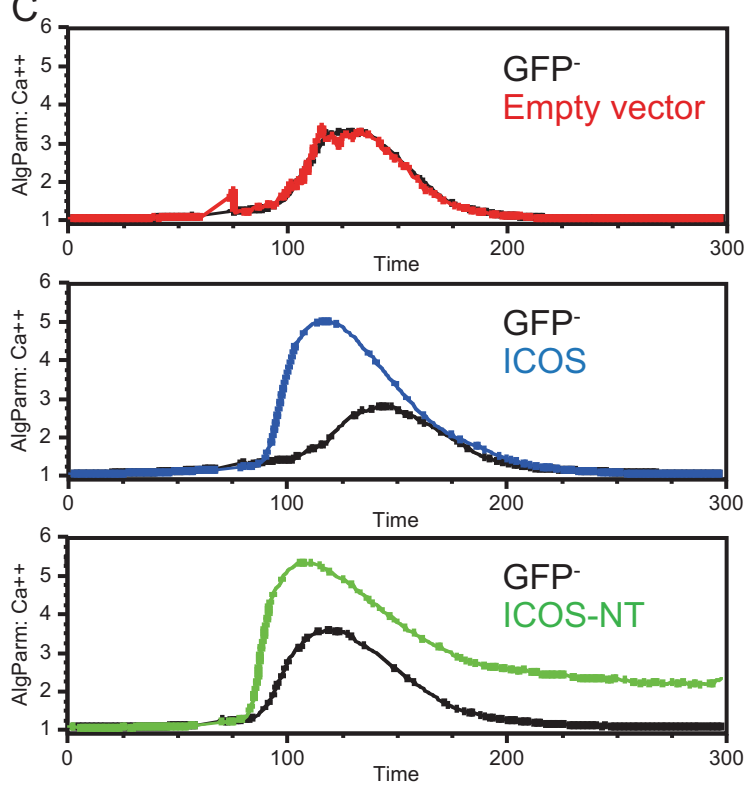

B

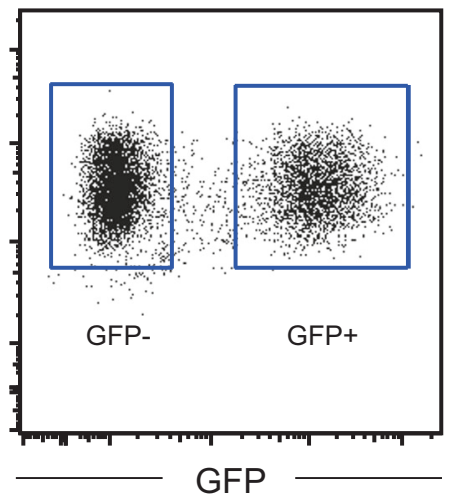

D
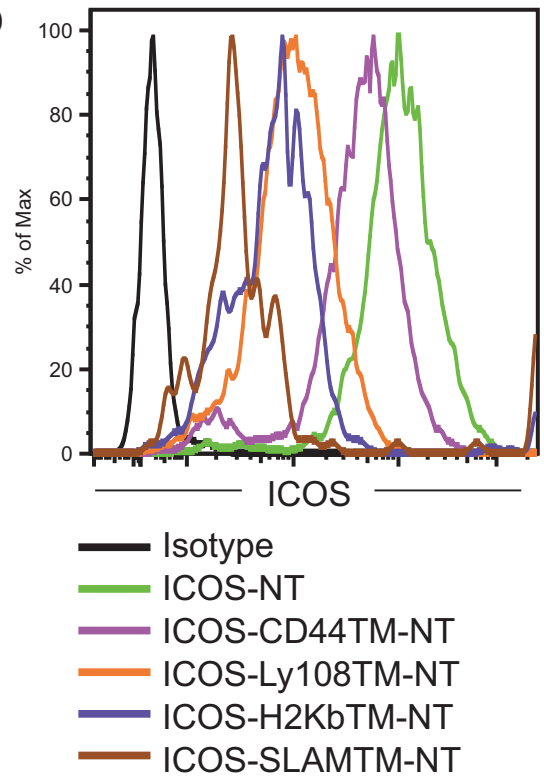

$E$

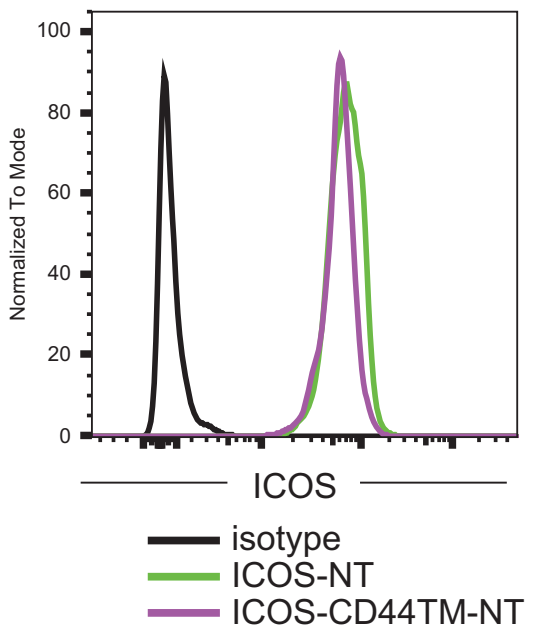

F
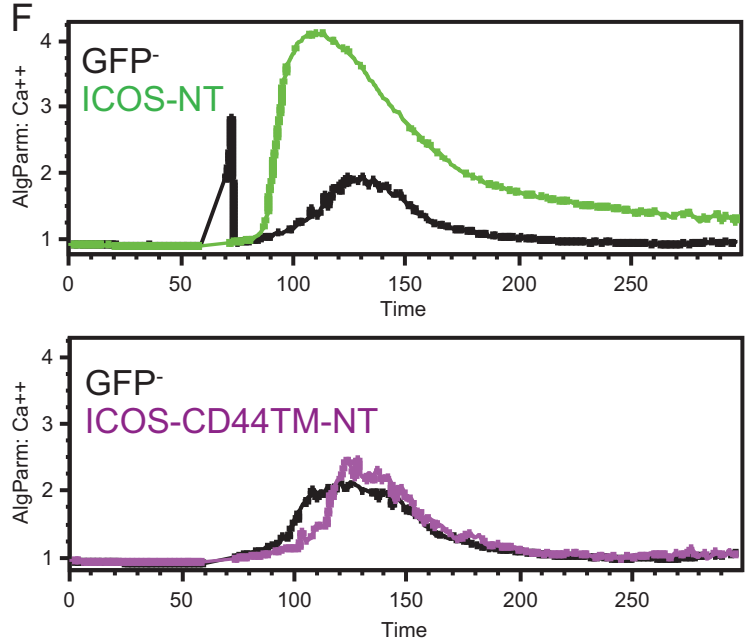

Fig. 1 The ICOS transmembrane domain, but not the cytoplasmic domain, mediates the costimulation of calcium mobilization. a Surface ICOS staining of Jurkat cells lentivirally transduced with an empty vector or vectors expressing full-length ICOS or ICOS-NT. b Example of gating $\mathrm{GFP}^{+}$stably transduced Jurkat cells and GFP ${ }^{-}$spike-in nontransduced control Jurkat cells for the calcium mobilization assay. c Calcium mobilization in Jurkat cells of the indicated types and the respective internal GFP' control cells after stimulation with biotinylated anti-CD3 $(0.2 \mu \mathrm{g} / \mathrm{ml})$ and anti-ICOS $(2 \mu \mathrm{g} / \mathrm{ml})$ antibodies coligated by streptavidin. The data represent the results of three independent experiments. d Surface ICOS staining of Jurkat cells lentivirally transduced with vectors expressing mutant ICOS molecules of the indicated types. e Surface ICOS staining after normalization of expression between ICOS-NT and ICOS-CD44TM-NT. $f$ Calcium mobilization in Jurkat cells of the indicated types conducted as for $\mathbf{c}$. The data represent the results of three independent experiments 
The ICOS cytoplasmic domain is clearly indispensable for mediating the PI3K activation that underlies follicular recruitment and the maintenance of helper $T$ cells during a GC response in vivo. ${ }^{10-12,18}$ However, ICOS plays a role in promoting CXCR5 upregulation within $24 \mathrm{~h}$ after antigen activation in vivo. ${ }^{13}$ To test whether ICOS-NT can be functional in vivo, $\mathrm{Icos}^{-1-}$ OT-II T cells transduced with ICOS or ICOS-NT were transferred into and activated in recipient mice following ovalbumin immunization. As shown in Figures S2C-E, control $/ \cos ^{-1-}$ OT-II T cells were not able to upregulate CXCR5 as efficiently as cells complemented with fulllength ICOS, consistent with previous observations, ${ }^{13}$ but the ICOS-NT clearly rescued the defect. Therefore, ICOS-NT can functionally signal in vivo, and the striking implication is that ICOS-mediated calcium costimulation does not rely on the cytoplasmic domain.

ICOS-mediated functions are extremely sensitive to ICOS expression levels on the plasma membrane, and a mere 2-fold reduction may lead to functional compromise. To probe ICOS signaling mechanisms, therefore, it was important to obtain cells expressing ICOS and its variants at uniform and comparable levels on the cell surface. This was difficult using primary $\mathrm{T}$ cells. We therefore constructed stable ICOS-expressing Jurkat cell lines by lentiviral transduction. Endogenous ICOS expression on Jurkat cells is minimal (Fig. 1a, "Empty vector"). Importantly, as predicted, at a similar level of surface expression, ICOS-NT exhibited an ability to enhance calcium flux triggered by TCR stimulation comparable to that of full-length ICOS (Fig. 1b, c).

Using Jurkat cells, Leconte and colleagues recently suggested a membrane-proximal KKKY motif in the ICOS cytoplasmic tail to be important for ICOS-mediated calcium costimulation, although surface expression of KKKY-mutated ICOS was severely compromised ${ }^{24}$ consistent with the fact that membrane-proximal polybasic residues promote efficient membrane-bound trafficking of transmembrane proteins. ${ }^{25-28}$ Those authors attempted to control for varied expression levels by simply applying a universal ICOS-expression gate during their calcium flux assays, even
A

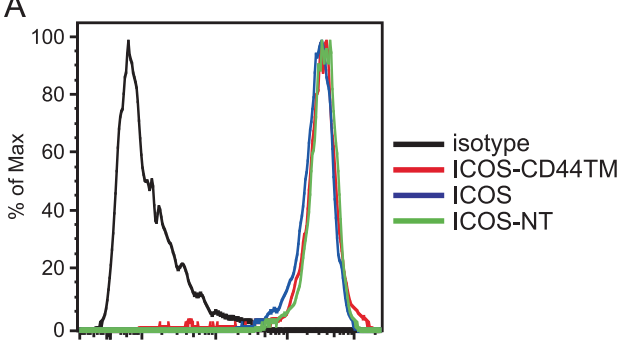

B

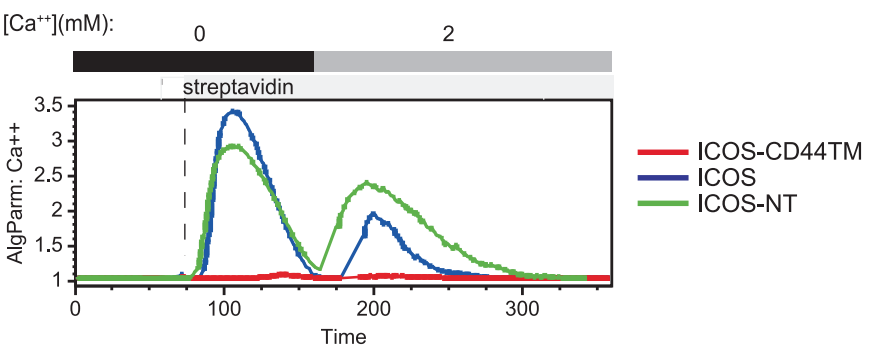

C

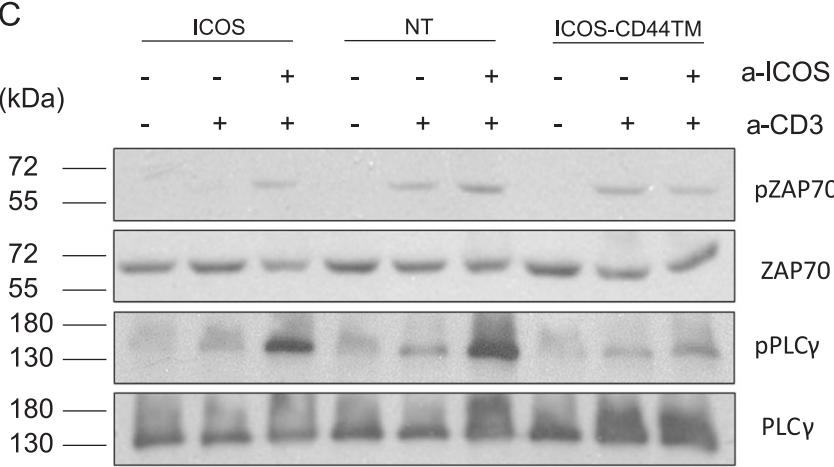

D

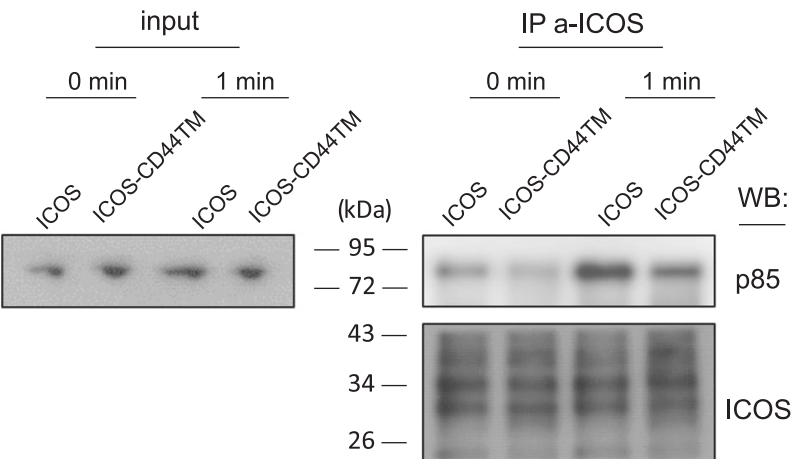

E
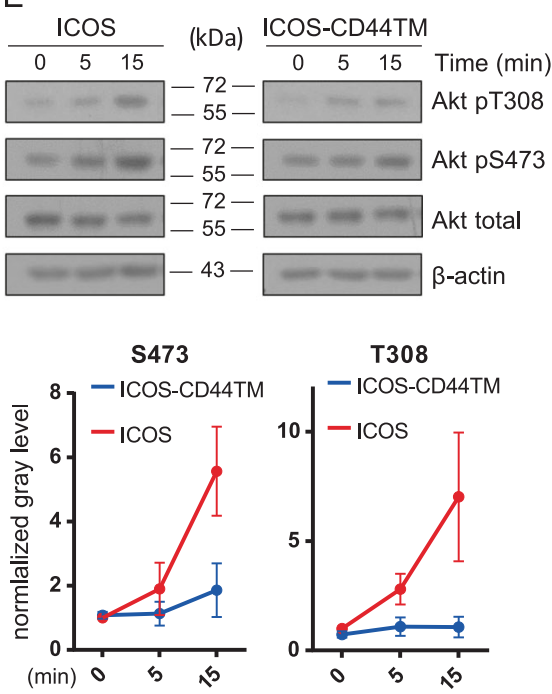
though gated cells still had overtly different levels of ICOS on the cell surface, precluding rigorous interpretations. Instead, we stringently normalized ICOS surface expression by sorting and subculturing Jurkat cells and found that ICOS-Y170F mutants, reported by Leconte et al. to impair calcium costimulation, were fully competent in costimulating calcium mobilization (Figures S3A-B).

Taken together, our findings rule out the possibility that a yetto-be-identified signaling motif in the ICOS cytoplasmic domain is responsible for calcium costimulation. An intriguing possibility is that the ICOS transmembrane domain (TMD) might somehow signal into the cell.

The ICOS transmembrane domain mediates the costimulation of calcium mobilization

To determine the potential role of the ICOS TMD, we constructed a series of hybrid ICOS-NT molecules that contained no cytoplasmic domain but rather contained the original ICOS extracellular domain anchored by different TMDs taken from other transmembrane protein molecules. Whereas the human ICOS TMD permitted similar levels of surface expression and supported costimulation of calcium mobilization with a high efficiency (Figures S4A-B), TMDs from $\mathrm{H} 2 \mathrm{~K}^{\mathrm{b}}$, SLAM, Ly108, and CD44 all led to compromised surface ICOS expression (Fig. 1d). By cell sorting and subculturing, it was possible to derive ICOS-CD44TM-NT and ICOS-NT Jurkat cells that expressed comparable levels of ICOS on the cell surface (Fig. 1e). After normalization of surface expression, we found that coligation of CD3 and ICOS-NT led to significant calcium mobilization, but the calcium flux was much weakened in ICOS-CD44TM-NT Jurkat cells (Fig. 1f). These data indicate that the ICOS TMD is required for the costimulation of calcium signaling by ICOS.

The ICOS transmembrane domain mediates costimulation by enhancing the proximal TCR signaling cascade

To test whether the effect of ICOS costimulation impinges on ER calcium release or only calcium release-triggered calcium entry, we stimulated ICOS, ICOS-NT, and ICOS-CD44TM (Figure S1) Jurkat cells first in the absence and then in the presence of extracellular calcium. ICOS-CD44TM cells exhibited a dramatic defect in ER calcium release, even though surface expression levels of ICOS were comparable among all the cells (Fig. 2a, b). Furthermore, coligation of CD3 with ICOS or ICOS-NT, but not with ICOSCD44TM, heightened ZAP70 and PLC- $\gamma$ phosphorylation compared with anti-CD3 stimulation alone (Fig. 2c). These results demonstrate that ICOS costimulation of calcium mobilization indeed involves enhancement of proximal TCR signaling events, which primarily involve a phosphorylation cascade. An intriguing possibility is that the ICOS TMD may be directly or indirectly associated with a kinase. Because some ICOS molecules are constitutively phosphorylated and bound by p85 without TCR stimulation or ligand engagement in previously activated T cells, a putative ICOS TMD-associated kinase would explain how ICOS can mediate phosphorylation-dependent PI3K activation.

The ICOS transmembrane domain is required for $\mathrm{p} 85$ recruitment and PI3K activation

We tested the prediction that the ICOS TMD is important for phosphorylation-dependent p85 recruitment to the ICOS cytoplasmic domain by examining p85 binding to ICOS before and after ICOS crosslinking. As shown in Fig. 2d, ICOS was constitutively bound by a certain level of p85, consistent with previous observations in recently activated primary T cells. ${ }^{16,18}$ On the other hand, p85 binding to ICOS-CD44TM molecules was markedly reduced, and this reduction was not corrected even after ICOS ligation. Consistent with this finding, enhanced Akt phosphorylation at T308 and S473 following ICOS ligation was significantly subdued when the CD44 transmembrane domain was used (Fig. 2e). These data demonstrate that the ICOS TMD is indeed important for phosphorylation-dependent p85 recruitment and PI3K activation under the steady-state and upon ICOS ligation, supporting the possibility that the ICOS TMD is associated with a kinase.

Lck is required for p85 recruitment to ICOS and for ICOS costimulation

Lck is the primary upstream kinase that phosphorylates CD3 ITAMs and ZAP70 (ref. ${ }^{29}$ ) and can be localized to the plasma membrane following myristylation and palmitylation ${ }^{30}$ To test whether Lck is required for ICOS functions, we used CRISPR technology to generate two independent clones of Lck-deficient Jurkat cells (Figure S5). After lentiviral transduction of ICOS, the two Lckdeficient clones were subjected to CD3 and ICOS coligation or CD3 stimulation alone. As shown in Fig. 3a, coligation failed to generate more calcium flux than anti-CD3 stimulation alone. Importantly, although the amount of ICOS that could be immunoprecipitated from LCK-deficient cells was consistently higher than that from LCK-sufficient cells, presumably due to the changed phosphorylation status of the molecule, p85 became essentially undetectable in the precipitates of the former (Fig. 3b), indicating that constitutive p85-ICOS binding depends on Lck. Therefore, Lck is functionally required for both ICOS-mediated calcium costimulation and constitutive PI3K activation.

Transmembrane domain-dependent ICOS-Lck association To test whether Lck is associated with the ICOS transmembrane domain, we first resorted to the proximity-dependent biotin

A
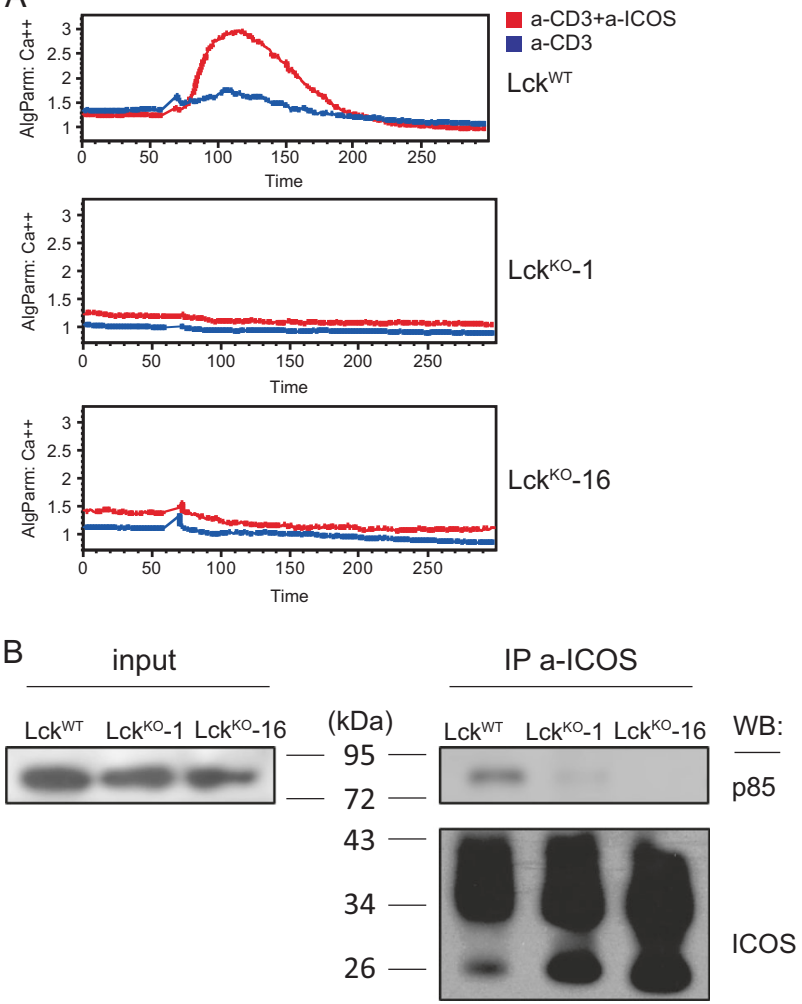

Fig. 3 Lck is required for p85 recruitment to ICOS and for ICOSmediated calcium costimulation. a Calcium mobilization by wildtype (WT) and LCK-knockout (KO) clone 1 and clone 16 Jurkat cells stably expressing wild-type ICOS after stimulation with anti-CD3 alone or anti-CD3 $(0.2 \mu \mathrm{g} / \mathrm{ml})$ and anti-ICOS $(2 \mu \mathrm{g} / \mathrm{ml})$ antibodies coligated by streptavidin. The data represent the results of three independent experiments. b Input (3\% total lysates) or anti-ICOS immunoprecipitates of the indicated wild-type and Lck-deficient Jurkat cells were immunoblotted for p85 and ICOS. The data represent the results of three independent experiments 
identification (BiolD) technology that can detect interactor proteins based on transient colocalization in living cells. ${ }^{20,31}$ ICOS and ICOS-CD44TM molecules were linked at the C-terminus to BirA* by a relatively rigid (EAAAK) $\times 3$ linker. After overnight culture in the presence of exogenous biotin, streptavidin immunoprecipitates of Jurkat cells expressing comparable levels of ICOS-BirA* or ICOS-CD44TM-BirA* molecules were probed for p85, Lck, and Fyn (Fig. 4a). As shown in Fig. 4b, p85 was strongly labeled in the ICOS group but not in the ICOS-CD44TM group, confirming the dependence of p85 recruitment on the ICOS transmembrane domain. More importantly, Lck was now clearly detected exclusively in the ICOS group, whereas ICOS-CD44TM cells failed to yield significant Lck biotinylation. On the other hand, both
ICOS-BirA* and ICOS-CD44TM-BirA* labeled a similar level of Fyn (Fig. 4b), an Src-family kinase mainly localized in the cytosol of T cells. ${ }^{32}$ Given that the effective labeling radius of $B i r A^{*}$ is $\sim 10 \mathrm{~nm}$, significant numbers of ICOS and Lck molecules must be associated with one another in close proximity to be labeled. We further probed the ICOS-LCk association by coimmunoprecipitation. To this end, ICOS-NT and ICOS-CD44TM-NT Jurkat cells that expressed comparable levels of surface ICOS and intracellular mCherry-tagged Lck were incubated with an anti-ICOS antibody, washed, and then subjected to immunoprecipitation to ensure probing of ICOS-Lck association at the plasma membrane. As shown in Fig. 4c, Lck coprecipitated with ICOS-NT but not as efficiently as with ICOS-CD44TM-NT. These data demonstrate that
A

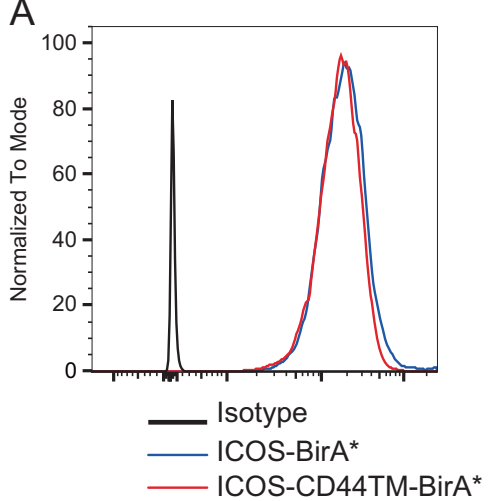

C

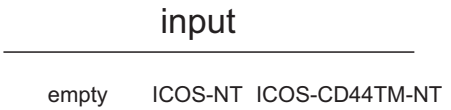

B

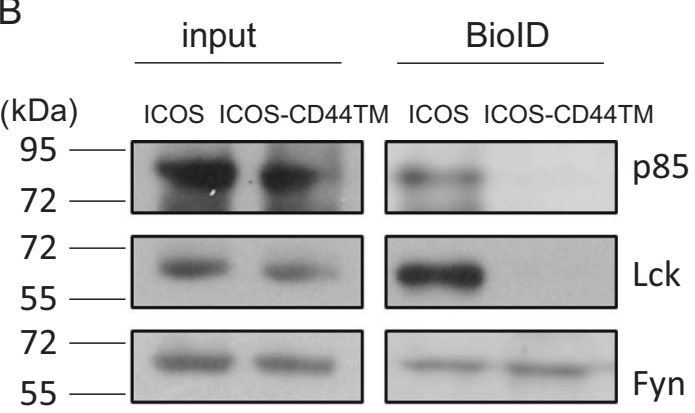

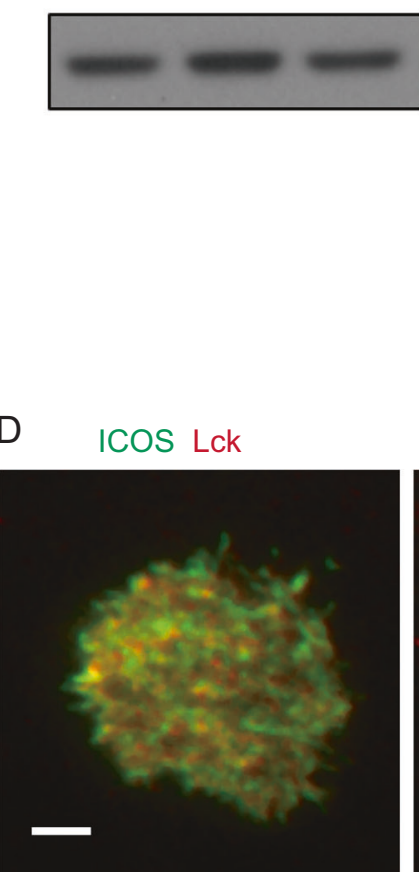
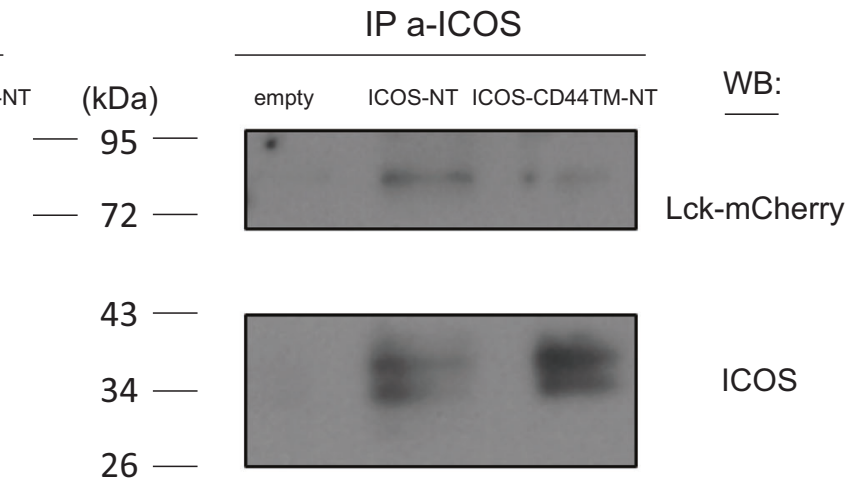

ICOS

26

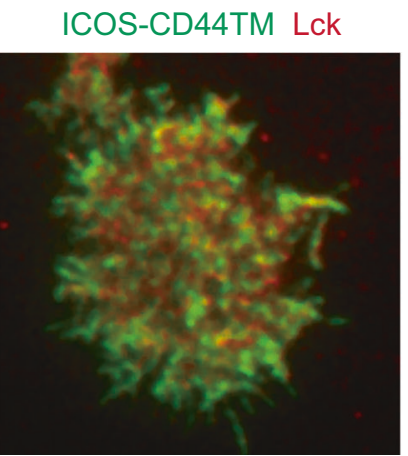

E

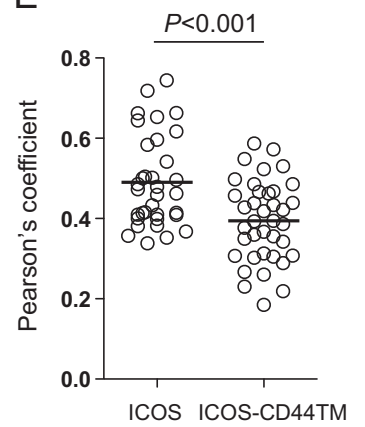

Fig. 4 Transmembrane domain-dependent ICOS-Lck association. a Surface ICOS staining of Jurkat cells stably expressing BirA*-tagged ICOS or ICOS-CD44TM molecules. b Immunoblotting of p85, Lck, and Fyn in total lysates (input) or streptavidin-precipitated proteins from Jurkat cells that stably expressed BirA*-tagged ICOS or ICOS-CD44TM molecules after $24 \mathrm{~h}$ of culture in the presence of exogenous biotin. The data represent the results of four independent experiments. c Input (3\% total lysates) or anti-ICOS immunoprecipitates of ICOS-NT or ICOSCD44TM-NT Jurkat cells transduced with mCherry-tagged Lck were immunoblotted for p85 and ICOS. The data represent the results of three independent experiments. d Representative TIRF-plane images of EGFP-tagged ICOS or ICOS-CD44TM (green) and mCherry-tagged Lck (red) on Jurkat cells $10 \mathrm{~min}$ after being placed on anti-ICOS-incorporated planar lipid bilayers. e Pearson's correlation coefficients for ICOS-LCk or ICOS-CD44TM-Lck colocalization on Jurkat cells. Each dot denotes one cell. The data presented were pooled from two independent experiments 
the ICOS TMD is indeed associated with Lck under steady-state conditions.

To further examine the ICOS-Lck association after ICOS ligation, we created Jurkat cells that expressed EGFP-tagged ICOS or ICOSCD44TM together with mCherry-tagged Lck. Ten minutes after these cells were placed on planar lipid bilayers that displayed an anti-ICOS antibody, Lck exhibited stronger colocalization with wild-type ICOS in the TIRF-imaged plane than with ICOS-CD44TM molecules (Fig. 4d, e). Together, these data strongly suggest that ICOS functions by associating with Lck in a TMD-dependent manner: Lck phosphorylates the YMFM motif to promote PI3K activation under steady-state conditions or after ICOS ligation in the bystander mode, and Lck is brought by ICOS to TCRs upon coligation to promote TCR-dependent calcium mobilization.

An important prediction of this model is that TMD-swapped ICOS cannot support normal $\mathrm{GC}$ and $\mathrm{T}_{\mathrm{FH}}$ development in vivo even when endowed with an intact cytoplasmic domain. Indeed, when we reconstituted $1 \cos ^{-1-}$ OT-II T cells with full-length ICOS or ICOSCD44TM and tested whether these cells could serve as competent helper T cells to promote GC formation, we found that only ICOS, not TMD-swapped ICOS-CD44TM, rendered competent helper T cells to support GC formation (Fig. 5a-c).
A
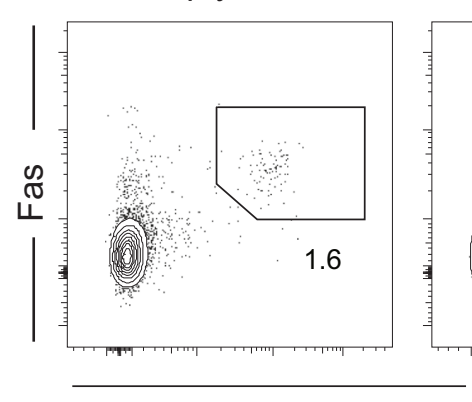

ICOS

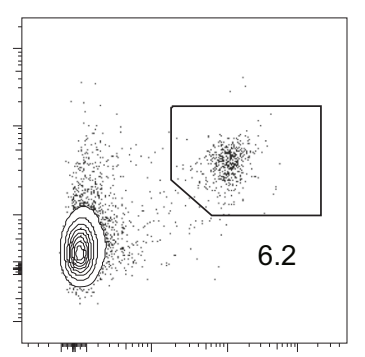

$\lg \mathrm{Ma}$

\section{ICOS-CD44TM}

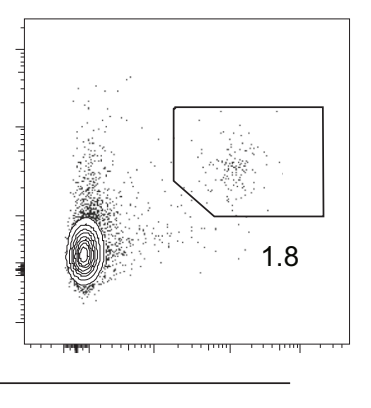

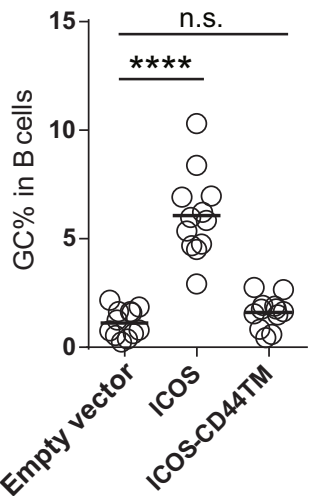

B
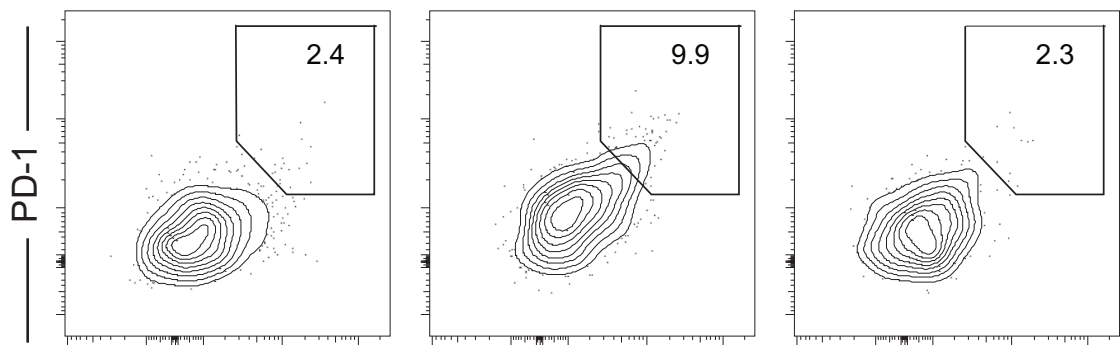

CXCR5

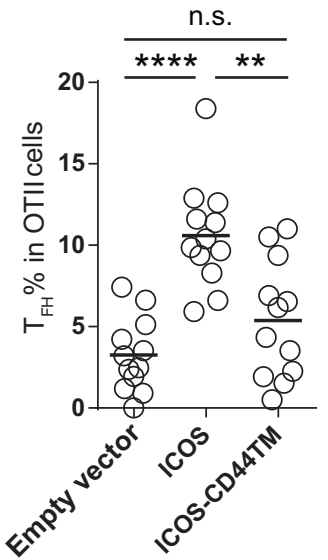

C

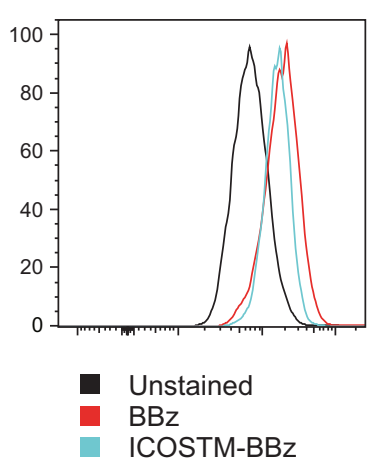

D
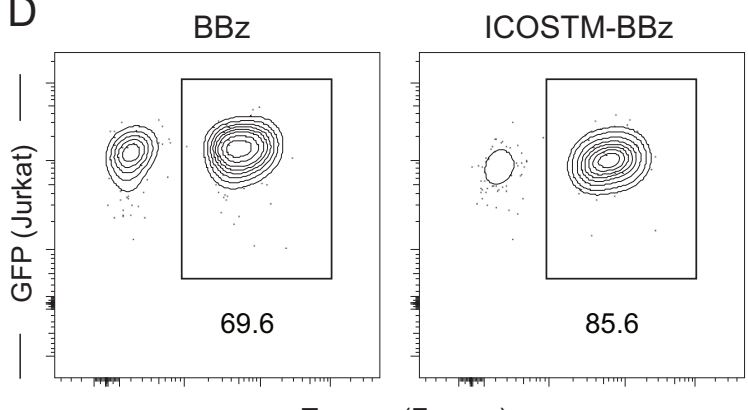

Tamara (Farage)

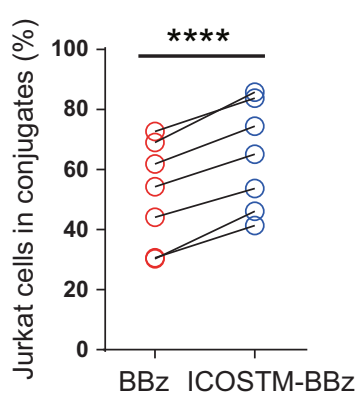

Fig. 5 ICOS transmembrane domain-mediated helper functions. $\mathbf{a}$, b Representative contour plots and frequencies of IgMa ${ }^{+}$Fas ${ }^{\text {hi }}$ GC B cells among the total CD19 ${ }^{+}$cells (a) and CXCR5 ${ }^{\text {hi }} \mathrm{PD}-1^{\mathrm{hi}} \mathrm{T}_{\mathrm{FH}}$ cells among the transferred OT-II cells (b). Each symbol in scatter plots represents one mouse, and the lines denote the means. The data presented were pooled from 3 independent experiments $(* * P<0.01$ and $* * * * P<0.0001$, as determined by Mann-Whitney tests). c Surface CAR staining of Jurkat cells lentivirally transduced to express CD19-reactive BBz CAR, which has the original CD8 transmembrane domain, or ICOSTM-BBz CAR, which has the ICOS transmembrane domain. d Representative FACS profiles (left; the numbers indicate the event percentages in the gates) and summarized frequencies of CAR-expressing Jurkat cells in conjugation with TAMARA-labeled CD $19^{+}$Farage $B$ cells (right). Each line connecting two dots represents one independent experiment ${ }^{* * * *} P<0.0001$, as determined by paired $t$-test) 
Modified chimeric antigen receptors with the ICOS

transmembrane domain

$T$ cells that carry tumor-specific chimeric antigen receptors (CAR) have been successfully used to combat B-cell tumors. ${ }^{33}$ Much effort has been made to optimize CARs to function more efficiently, and cytoplasmic signaling motifs from various immune molecules are important building blocks in the CAR-engineering toolbox. ${ }^{34}$ Given the Lck-associating nature of the ICOS TMD, we replaced the $C D 8$ transmembrane domain in the standard CD19reactive FMC63-BBz CAR (BBz CAR) with the ICOS TMD (ICOSTM$B B z(A R)$ and tested the two types of receptors in Jurkat cells. As shown in Fig. $5 d-f$, when incubated with Farage B cells, Jurkat cells carrying ICOSTM-BBz CAR yielded more frequent T-B conjugates, indicating that the ICOS TMD can function as a signaling component independent of its native molecular context and may be useful for engineering CARs with enhanced functions.

\section{DISCUSSION}

A surprising insight of the current study is that the ICOS TMD signals by mediating an association with Lck. In principle, this association may involve ICOS interactions with another transmembrane proteins that can physically bind to Lck, for example, CD4, CD8, or CD28. However, the parental Jurkat cells we use do not express CD4, and CRISPR/Cas9-mediated CD28 deletion did not diminish ICOS-mediated costimulation (our unpublished data). Charged residues in the TMDs of TCR and CD3 chains help establish their intermolecular association in defined stoichiometry, ${ }^{35}$ although ICOS does not have any charged residues in its TMD. It is also possible that the ICOS TMD directly, or indirectly through other lipid species, interacts with the membraneembedded myristyl and/or palmityl moieties of acylated Lck molecules. In this regard, it is interesting to note that both human and mouse ICOS TMDs contain cysteine residues, which can in principle be acylated. However, alanine replacement of these cysteines did not affect the ICOS-mediated costimulation of calcium signaling (our unpublished data). Furthermore, when alanines were used to substitute for strings of 5 amino acids in the TMD starting from the outer and going into the inner leaflet of the plasma membrane, no obvious motif could be clearly defined as being essential for calcium costimulation beyond the fact that such substitution reduced the level of surface ICOS (our unpublished data). Therefore, further tests of the abovementioned possibilities and precise elucidation of the biochemical and biophysical natures of the ICOS TMD-Lck association await improved tools for studying protein-lipid interactions and in vitro reconstitution of the signaling apparatus.

These uncertainties notwithstanding, Lck association would explain the three-tiered signaling functions that ICOS mediates for activated T cells: ligand-independent and TCR-independent p85 binding and $\mathrm{PI} 3 \mathrm{~K}$ activation under steady-state conditions, ligation-enhanced but TCR-independent PI3K activation, and enhancement of the TCR proximal signaling cascade upon coligation with the antigen receptor complex. Even without receptor ligation or TCR stimulation, ICOS can associate with Lck at a level that can be detected by both the BiolD method and coimmunoprecipitation. When ICOS is crosslinked, the ICOS-Lck association most likely becomes stronger and more widespread at the cell membrane to mediate more robust p85 recruitment and PI3K activation. In combination, these observations explain how ICOS itself can apparently maintain its phosphorylated state and activate the PI3K pathway, a process that is of crucial importance for follicular T-cell recruitment and $\mathrm{T}_{\mathrm{FH}}$ maintenance by follicular $\mathrm{B}$ cells in vivo. ${ }^{10,12}$ Given that the pool of Lck available to signal TCR is a limiting factor for signal initiation and propagation, ${ }^{29,36}$ Lck association would also mean that the ICOS receptor can bring more Lck molecules to TCR complexes that are coligated, thus explaining how ICOS can costimulate calcium mobilization triggered by low-level TCR stimulation, a process that is particularly important for antigen-specific T-B interactions in the germinal center. ${ }^{15}$ These findings, combined with the observation that the ICOS transmembrane domain functions independently of its native molecular context in our proof-of-principle CAR experiments, also offer a likely explanation for the recent report that third-generation CAR T cells carrying the ICOS transmembrane domain persist better and are more efficient at clearing tumor cells in NSG mice than those without the domain. ${ }^{37}$

\section{ACKNOWLEDGEMENTS}

The authors thank Dr. C. Xu for assistance with the CAR construction. This work was funded in part by the Ministry of Science and Technology "973" program (Grant No. 2014CB542501), the National Natural Science Foundation of China (Grant Nos. 81330070, 81425011, 81621002, and 81761128019), and the Tsinghua-Peking Center for Life Sciences. This work was also funded in part by the Bill \& Melinda Gates Foundation and the Howard Hughes Medical Institute. The findings and conclusions within are those of the authors and do not necessarily reflect the positions or policies of the Bill \& Melinda Gates Foundation or the Howard Hughes Medical Institute.

\section{AUTHOR CONTRIBUTIONS}

H.Q. conceptualized and supervised the study and wrote the paper with Z.W. Z.W. conducted the majority of the experiments and designed the BioID part of the study. X.S. performed immunoprecipitation, immunoblotting, and CAR-related experiments with Z.W. and conducted molecular imaging analyses together with X.J. L.D., J.W., and Z.X. helped with molecular cloning and the creation of the cell lines. W.L. designed and supervised the imaging experiments. All authors contributed to data interpretation.

\section{ADDITIONAL INFORMATION}

The online version of this article (https://doi.org/10.1038/s41423-018-0183-z) contains supplementary material.

Competing interests: The authors declare no competing interests.

Publisher's note: Springer Nature remains neutral with regard to jurisdictional claims in published maps and institutional affiliations.

\section{REFERENCES}

1. Hutloff, A. et al. ICOS is an inducible T-cell co-stimulator structurally and functionally related to CD28. Nature 397, 263-266 (1999).

2. Yoshinaga, S. K. et al. T-cell co-stimulation through B7RP-1 and ICOS. Nature 402, 827-832 (1999).

3. Crotty, S. Follicular Helper CD4 T Cells $\left(\mathrm{T}_{\mathrm{FH}}\right)$. Annu. Rev. Immunol. 29, 621-663 (2011).

4. Coyle, A. J. et al. The CD28-related molecule ICOS is required for effective T celldependent immune responses. Immunity 13, 95-105 (2000).

5. Dong, $\mathrm{C}$. et al. ICOS co-stimulatory receptor is essential for T-cell activation and function. Nature 409, 97-101 (2001).

6. Dong, C., Temann, U. A. \& Flavell, R. A. Cutting edge: critical role of inducible costimulator in germinal center reactions. J. Immunol. 166, 3659-3662 (2001).

7. McAdam, A. J. et al. ICOS is critical for CD40-mediated antibody class switching. Nature 409, 102-105 (2001)

8. Tafuri, A. et al. ICOS is essential for effective T-helper-cell responses. Nature 409, 105-109 (2001).

9. Choi, Y. S. et al. ICOS receptor instructs T follicular helper cell versus effector cell differentiation via induction of the transcriptional repressor Bcl6. Immunity 34, 1-15 (2011).

10. Weber, J. P. et al. ICOS maintains the T follicular helper cell phenotype by downregulating Kruppel-like factor 2. J. Exp. Med. 212, 217-233 (2015).

11. Qi, H. T follicular helper cells in space-time. Nat. Rev. Immunol. 16, 612-625 (2016).

12. $\mathrm{Xu}, \mathrm{H}$. et al. Follicular T-helper cell recruitment governed by bystander $\mathrm{B}$ cells and ICOS-driven motility. Nature 496, 523-527 (2013). 
13. Chen, X., Ma, W., Zhang, T., Wu, L. \& Qi, H. Phenotypic Tfh development promoted by CXCR5-controlled re-localization and IL-6 from radiation-resistant cells. Protein Cell 6, 825-832 (2015).

14. Pedros, C. et al. A TRAF-like motif of the inducible costimulator ICOS controls development of germinal center TFH cells via the kinase TBK1. Nat. Immunol. 17, 825-833 (2016)

15. Liu, D. et al. T-B-cell entanglement and ICOSL-driven feed-forward regulation of germinal centre reaction. Nature 517, 214-218 (2015).

16. Feito, M. J. et al. Mechanisms of H4/ICOS costimulation: effects on proximal TCR signals and MAP kinase pathways. Eur. J. Immunol. 33, 204-214 (2003).

17. Parry, R. V., Rumbley, C. A., Vandenberghe, L. H., June, C. H. \& Riley, J. L. CD28 and inducible costimulatory protein Src homology 2 binding domains show distinct regulation of phosphatidylinositol 3-kinase, $\mathrm{Bcl}-\mathrm{xL}$, and IL-2 expression in primary human CD4 T lymphocytes. J. Immunol. 171, 166-174 (2003).

18. Gigoux, M. et al. Inducible costimulator promotes helper T-cell differentiation through phosphoinositide 3-kinase. Proc. Natl Acad. Sci. USA 106, 20371-20376 (2009).

19. Nurieva, R. I. et al. A costimulation-initiated signaling pathway regulates NFATC1 transcription in T lymphocytes. J. Immunol. 179, 1096-1103 (2007)

20. Roux, K. J., Kim, D. I., Raida, M. \& Burke, B. A promiscuous biotin ligase fusion protein identifies proximal and interacting proteins in mammalian cells. J. Cell. Biol. 196, 801-810 (2012).

21. Liu, W., Meckel, T., Tolar, P., Sohn, H. W. \& Pierce, S. K. Intrinsic properties of immunoglobulin IgG1 isotype-switched B cell receptors promote microclustering and the initiation of signaling. Immunity 32, 778-789 (2010).

22. Garside, P. et al. Visualization of specific B and T lymphocyte interactions in the lymph node. Science 281, 96-99 (1998).

23. Chu, C. et al. SAP-regulated T cell-APC adhesion and ligation-dependent and -independent Ly108-CD3zeta interactions. J. Immunol. 193, 3860-3871 (2014).

24. Leconte, J., Bagherzadeh Yazdchi, S., Panneton, V. \& Suh, W. K. Inducible costimulator (ICOS) potentiates TCR-induced calcium flux by augmenting PLCgamma1 activation and actin remodeling. Mol. Immunol. 79, 38-46 (2016).

25. Parmar, H. B., Barry, C. \& Duncan, R. Polybasic trafficking signal mediates golgi export, ER retention or ER export and retrieval based on membrane-proximity. PLoS ONE 9, e94194 (2014).

26. Hancock, J. F., Paterson, H. \& Marshall, C. J. A polybasic domain or palmitoylation is required in addition to the CAAX motif to localize p21ras to the plasma membrane. Cell 63, 133-139 (1990).

27. Dong, C. et al. A triple arg motif mediates alpha(2B)-adrenergic receptor interaction with Sec24C/D and export. Traffic 13, 857-868 (2012).
28. Bonifacino, J. S. \& Traub, L. M. Signals for sorting of transmembrane proteins to endosomes and lysosomes. Annu. Rev. Biochem. 72, 395-447 (2003).

29. Courtney, A. H., Lo, W. L. \& Weiss, A. TCR signaling: mechanisms of initiation and propagation. Trends Biochem. Sci. 43, 108-123 (2017)

30. Resh, M. D. Myristylation and palmitylation of Src family members: the fats of the matter. Cell 76, 411-413 (1994).

31. Varnaite, R. \& MacNeill, S. A. Meet the neighbors: mapping local protein interactomes by proximity-dependent labeling with BiolD. Proteomics 16, 2503-2518 (2016).

32. Ley, S. C., Marsh, M., Bebbington, C. R., Proudfoot, K. \& Jordan, P. Distinct intracellular localization of Lck and Fyn protein tyrosine kinases in human T lymphocytes. J. Cell. Biol. 125, 639-649 (1994).

33. Brudno, J. N. \& Kochenderfer, J. N. Chimeric antigen receptor T-cell therapies for lymphoma. Nat. Rev. Clin. Oncol. 15, 31-46 (2018).

34. Schubert, M. L., Hoffmann, J. M., Dreger, P., Muller-Tidow, C. \& Schmitt, M. Chimeric antigen receptor transduced T cells: tuning up for the next generation. Int. J. Cancer 142, 1738-1747 (2017).

35. Wucherpfennig, K. W., Gagnon, E., Call, M. J., Huseby, E. S. \& Call, M. E. Structural biology of the T-cell receptor: insights into receptor assembly, ligand recognition, and initiation of signaling. Cold Spring Harb. Perspect. Biol. 2, a005140 (2010).

36. Davis, S. J. \& van der Merwe, P. A. The kinetic-segregation model: TCR triggering and beyond. Nat. Immunol. 7, 803-809 (2006).

37. Guedan, S. et al. Enhancing CAR T cell persistence through ICOS and 4-1BB costimulation. JCI Insight 3, e96976 (2018).

\section{(c) (i)}

Open Access This article is licensed under a Creative Commons Attribution 4.0 International License, which permits use, sharing, adaptation, distribution and reproduction in any medium or format, as long as you give appropriate credit to the original author(s) and the source, provide a link to the Creative Commons license, and indicate if changes were made. The images or other third party material in this article are included in the article's Creative Commons license, unless indicated otherwise in a credit line to the material. If material is not included in the article's Creative Commons license and your intended use is not permitted by statutory regulation or exceeds the permitted use, you will need to obtain permission directly from the copyright holder. To view a copy of this license, visit http://creativecommons. org/licenses/by/4.0/.

(c) The Author(s) 2018 